\title{
O CONCEITO DE PRODUÇÃO TEXTUAL NAS OCEM: UM CASO DE TRANSPOSIÇÃO DIDÁTICA
}

\author{
THE CONCEPT OF TEXT PRODUCTION IN THE \\ OCEM: A CASE OF DIDACTIC TRANSPOSITION
}

\author{
Denise Lino de Araújo ${ }^{1}$ \\ Antônio Naéliton do Nascimento ${ }^{2}$
}

\begin{abstract}
RESUMO: Documentos normativos de ensino, ainda que supostamente neutros, expõem um conjunto de concepções, princípios e orientações, que podem vir a influenciar a prática docente. Diante disso, tomamos como documento nesta pesquisa as Orientações Curriculares para o Ensino Médio (OCEM, 2006), que se apresentam como um instrumento didático capaz de dar suporte ao professor na seleção de procedimentos teórico-metodológicos a serem adotados no ensino-aprendizagem. Levando em consideração a área de Linguagens e a disciplina de Língua Portuguesa, este trabalho tem como foco apresentar a (des)montagem (Le Goff, 1997) da arquitetura conceitual do documento, cujas opções teóricas não estão indicadas no corpo do texto. A partir de pesquisa documental, de base qualitativo-interpretativista e situada no campo críticocolaborativo da Linguística Aplicada (LA), investigamos a Transposição Didática (CHEVALLARD, 1991) que (re)define o conceito de Produção Textual. Para tal investigação, apoiamo-nos na teoria da Transposição Didática, Chevallard (1991), Marandino (2004); em conceitos de Produção Textual, Bentes (2004), Koch (2009); e nos Estudos sobre Currículo, Silva (2005) e Macedo (2012). Os resultados apontam para uma concepção de produção textual articulada com outras noções e em consonância com os estudos linguísticos mais recentes, possuindo notável coerência teórica. Isso parece conferir uma natureza mais pedagógica e menos técnica ao objeto de ensino em referência, pressupondo um professor conhecedor das teorias com as quais este currículo foi elaborado.
\end{abstract}

Palavras-chave: Transposição Didática; OCEM; Produção Textual.

ABSTRACT: Normative teaching documents, although supposedly neutral, reveal a group of conceptions, principles, and orientations that can influence the teacher's practice. In light of this, in this research the primary focus was on the Orientações Curriculares para o Ensino Médio (OCEM, 2006), which are a didactic instrument capable of supporting the teacher in terms of theoretical and methodological procedures to be adopted in his or hers classroom. This paper aims at presenting the deconstruction (LE GOFF, 1997) of the document's conceptual framework, whose theoretical options are not clearly stated in the body of the text. From a documental research, of qualitative and interpretative basis and situated in the Applied Linguistics field, the Didactic Transposition (CHEVALLARD, 1991) claims and ideas which (re)define the concept of Text Production were investigated. Said investigation is supported by the Didactic Transposition theory, Chevellard (1991), Marandino (2004); by the Text Production concepts, Bentes (2004), Koch (2009); and by the Curriculum Studies approaches, Silva (2005) e Macedo (2012). The results suggest a notion of text production articulated with other views and in line with more recent linguistic studies, having, therefore, notable theoretical coherence. This seems to imply a more pedagogical and less technical nature to the aforesaid way of teaching, which

\footnotetext{
${ }^{1}$ Doutora em Educação pela Universidade de São Paulo (USP). Professora associada da Unidade Acadêmica de Letras (UAL) e do Programa de Pós-graduação em Linguagem e Ensino (PPGLE) da Universidade Federal de Campina Grande (UFCG). E-mail: deniselinoaraujo@gmail.com

${ }^{2}$ Graduando do Curso de Letras - Língua Portuguesa, da Unidade Acadêmica de Letras (UAL) - Universidade Federal de Campina Grande (UFCG). E-mail: 2naelyton2010@hotmail.com
} 
presupposes a teacher that knows to some extent the theories with which the indicated curriculum was elaborated.

Keywords: Didactic Transposition; OCEM; Text Production.

\section{Introdução}

Documentos normativos de ensino são "escritos por várias vozes e resultam de interesses conflitantes e de posições divergentes" (PETITJEAN, 2008, p. 04), uma vez que em sua composição fazem-se escolhas sobre que conceitos e procedimentos serão mobilizados pelos alunos, de modo que tais orientações podem ser prestigiadas ou não pelos agentes do sistema didático com suas diferentes representações de mundo. $\mathrm{Na}$ esteira dos vários documentos/discursos oficiais, tomamos como documento norteador neste artigo as Orientações Curriculares para o Ensino Médio (doravante OCEM) em virtude da força que tal documento tem na esfera educacional, visto que é um marco na (re)construção de currículos em Língua Materna.

As Orientações Curriculares para o Ensino Médio surgem a partir do disposto na LDB n ${ }^{\circ}$ 9.394/96 (BRASIL, 1996), em seu Art. 26, que levanta a importância de se ter uma base nacional comum para o ensino básico. Diante disso, "representações das universidades, Secretarias Estaduais de Educação e os professores articularam-se e colaboraram com a produção do documento em sua versão final" (OCEM, 2006, p. 08). As OCEM apresentam propostas para auxiliarem o professor em sua prática didática, esse documento não se coloca como um manual a ser seguido, mas como um instrumento capaz de dar o suporte necessário ao professor quanto aos procedimentos teórico-metodológicos a serem adotados.

Portanto, diante da interface que o documento conjuga com o campo do Currículo, não podemos ter uma visão restrita dos fenômenos que o cercam. Fatores como espaço, território de relações de poder, lugar em que identidades são forjadas (SILVA, 2005) não podem ser negligenciados na investigação deste documento curricular. Para estudá-lo, apoiamo-nos em Le Goff (1997) que, ao apresentar a ideia de "documento-monumento", chama atenção para o fato de que toda estrutura que o reveste precisa ser desmontada, "porque é em primeiro lugar uma roupagem, uma aparência enganadora, uma montagem. É preciso começar por desmontar, demolir esta montagem, desestruturar esta condição e analisar essas condições de produção de documentosmonumentos" (LE GOFF, 1997, p. 104).

Nessa direção, essa pesquisa ${ }^{3}$ está assentada à luz de uma abordagem de natureza qualitativa, de caráter interpretativista, em que, para a análise dos dados, levam-se em conta suas peculiaridades e seu contexto. É preciso, portanto, contemplá-los sob uma perspectiva panorâmica e multilateral, uma vez que os dados são verbais e abrangem as subjetividades dos agentes envolvidos e os posicionamentos encontrados na tessitura do documento em pauta, ambos merecendo ser observados em sua singularidade.

No que diz respeito ao tipo de pesquisa, podemos caracterizá-la, em primeiro lugar, como documental, visto que o objeto analisado é uma proposta curricular, neste caso, as OCEM. Portanto, o levantamento dos dados ocorrerá por meio desta fonte de informações. Em segundo lugar, quanto aos objetivos, temos também uma pesquisa que se classifica como exploratória (MOREIRA; CALEFFE, 2008), posto que visa a esclarecer conceitos e tornar problemas mais precisos quanto à resolução de um dado fenômeno, neste caso, a filiação teórica do documento.

Para isso, este estudo insere-se no campo indisciplinar e crítico-colaborativo da Linguística Aplicada (LA), explorando sua interface com a área de Educação. Nessa perspectiva, entendemos a LA como "um modo de criar inteligibilidade sobre problemas sociais em que a linguagem tem um papel central" (MOITA LOPES, 2006, p. 14), ou seja, em contextos situados de uso da lin-

\footnotetext{
${ }^{3}$ Este artigo é fruto de uma pesquisa mais ampla, a nível de PIBIC/CNPq, realizada no âmbito da Universidade Federal de Campina Grande (UFCG).
} 
guagem podemos capturar as várias faces do nosso objeto. Como assinalam Silva e Alvarez (2008, p. 12), essa área de estudos reconhece questões urgentes de ordem linguística perpassadas por outros fatores, logo, práticas sociais são traduzidas, encaminhando-se soluções para a superação dos limites encontrados.

Assim sendo, diante da complexidade do documento em questão e dos aspectos acima citados, procuramos investigar a Transposição Didática (cf. CHEVALLARD, 1991), ou seja, a passagem do saber sábio ao saber escolarizável, em que, para o autor citado, é este o processo de transformações adaptativas que fabrica objetos de ensino. Dentre os vários objetos de ensino em língua materna, o objeto que investigamos é a Produção Textual, em relação ao qual visamos desvelar como ocorre sua didatização no âmbito de uma Transposição Didática (TD) externa, que ocorre nas instâncias oficiais a partir de documentos norteadores (como o caso das OCEM), legislação, livros didáticos, etc.

No campo dos estudos do currículo, do qual emerge o nosso objeto, é imprescindível observar a formação do discurso, questões político-ideológicas e de que modo influenciam a organização dos saberes didatizados, sobretudo a (re)configuração de conceitos. As noções que compõem o nosso objeto, Produção Textual, são estudadas por várias correntes da Linguística que têm o texto como elemento central. Em torno destas concepções de texto e gênero, formula-se um conceito de produção textual, envolvendo escrita e oralidade, assim, temos como objetivo neste artigo analisar a configuração teórica (dessincretização, em termos de TD) da produção textual, assim como apontar que implicações para o ensino de língua materna decorrem desse movimento didático observado num currículo voltado ao ensino médio.

Diante das condições supracitadas, um dos fatores que ratifica a relevância desta pesquisa dar-se-á pelo fato de que, no Brasil, parece haver pouca produção acadêmica que reúna estudos que relacione temas como TD Externa, Objetos de Ensino, Montagem de Currículos e Produção Textual. Além disso, esta investigação oferece contribuições específicas à discussão sobre organização de currículos para o ensino de língua materna no ensino médio (EM). Partindo desse pressuposto, faz-se necessária uma desmontagem (LE GOFF, 1997) do objeto investigado, objetivando elucidar a arquitetura conceptual dentro de uma arquitetura estrutural de que ele se reveste.

Para isso, este texto é composto de cinco partes, a saber: (1) Esta introdução; (2) Fundamentação Teórica; (3) Análise dos dados; (4) Considerações finais e (5) Referências. A seguir, passemos aos fundamentos teóricos de nossa pesquisa.

\section{O campo do currículo, transposição didática e produção textual: interligando conceitos}

Em tempos de transição curricular, como vivemos no Brasil, mostra-se cada vez mais recorrente o debate acerca de um tema controverso: o currículo. Como este campo é atravessado por lutas e resistências (Cf. SILVA, 2005), a composição de uma proposta curricular como as OCEM gerou debate em torno de sua elaboração por sugerir conteúdos comuns (mínimos) a todo aluno situado no território nacional, independentemente das diferenças socioculturais. Dentre os vários objetos de conhecimento transpostos neste currículo, podemos destacar a produção textual (oral e escrita) que, ao aparecer como um objeto de ensino num currículo, sofre transformações adaptativas, tanto em sua natureza teórica (conteúdo) quanto na metodológica (ação de ensinar).

Currículos são, sem dúvida, objetos compostos por faces complexas e multifacetadas. A sua influência provavelmente constitui-se como elemento basilar na construção de propostas de ensino, assim como admite-se que reflete ideologias e opções teóricas nos manuais de ensino aos quais se associa, conforme aponta Silva (2005). Diante disso, entendemos este artefato como produto de uma costura (MACEDO, 2012) a partir da qual saberes são organizados. Por se tratar de um tema controverso, para chegar a sua validação enquanto campo, o currículo teve que per-

https://periodicos.unifap.br/index.php/letras

Macapá, v. 9, n. 3, $2^{\circ}$ sem., 2019 
correr momentos, apropriando-se das contribuições de cada época, consolidando-se na virada do século XIX para o século XX. Na composição de sua "costura" estão diferentes concepções, decorrentes das teorias tradicionais, críticas ou pós-críticas, as quais se encontram indissociadas em seu processo de montagem.

Essas três teorias são bem descritas por Silva (2005). O estudioso define, quanto às teorias tradicionais de currículo, que este conceito decorre de uma concepção de mecanização curricular, postulada na primeira metade do século XX por John Franklin Bobbitt. De acordo com Silva (2005), temos uma concepção de currículo imerso num paradigma cientificista, tecnicista, centrado no professor e que via os alunos como passivos. Desse contexto, podemos depreender a ligação com o determinismo, sobretudo com o processo crescente de industrialização e urbanização.

Ainda de acordo com os estudos de Silva (2005), no que diz respeito às teorias críticas do currículo, podemos reconhecer que surgiram na década de 60 do século passado e que se assumiram como um movimento de renovação e resistência, com vistas a abalar as teorias tradicionais. Desse modo, essas teorias assentavam-se em concepções marxistas, Escola de Frankfurt, e da Nova Sociologia da Educação (NSE). Enquanto as teorias tradicionais ocupavam-se em como elaborar o currículo, em contrapartida, as teorias críticas voltam-se aos arranjos sociais e educacionais, colocando em pauta as injustiças e desigualdades.

Além dessas duas teorias, há ainda as teorias pós-críticas do currículo, as quais surgem a partir das décadas de 70 e 80 do século XX, fundamentando-se em princípios da fenomenologia, do pós-estruturalismo e dos estudos multiculturais. De acordo com Silva (2005), para esses estudos o que de fato importava seriam os significados subjetivos, as experiências manifestadas pela linguagem, pois os conteúdos eram vistos como construções sociais. Segundo Silva (2006), são esses estudos associados à "virada linguística" que modificaram radicalmente as concepções iniciais, sobretudo por apontarem para o valor histórico e social do conhecimento, os quais se encontram interligados quando os saberes são transpostos, remodelados, transformados e organizados no âmbito de um currículo a partir da didatização.

Esse processo didático é estudado por Chevallard (1991) que, para analisar as transformações adaptativas do saber, propõe um modelo teórico chamado "Transposição Didática capaz de entender a dinâmica dos sistemas de ensino". Conforme aponta Marandino (2004), o saber científico ganha os espaços sociais com os quais dialoga, provocando mudanças e, ao mesmo tempo, sofrendo-as. Partindo desse pressuposto, entendemos a Transposição Didática (TD) como a passagem do saber científico ao saber escolar, isto é, a transformação em um objeto de ensino.

Conforme pontua Petitjean (2008), a transposição didática externa é efetuada por redatores de programas, autores de artigos, de manuais, currículos. Já a TD interna é realizada pelos próprios professores, no exercício da docência, enquanto que a TD externa dar-se-á quando atores sociais engajados ou até mesmo uma comunidade científica compartilham referências de linguagem, teorias, métodos (FÁVERO; TAUCHEN; SCHWANTES, 2012) e os reúnem em documentos que os validem, produzindo saberes disciplinares que são recortes dos saberes científicos. A esse respeito, Petitjean (2008) aponta cinco procedimentos/operações a partir dos quais podemos enxergar a dinâmica da transposição, a saber: dessincretização, despersonalização, programabilidade, publicidade e controle.

A dessincretização consiste em extrair um saber de seu campo científico, isto é, transformálo em um objeto de ensino (recontextualizado). Já a despersonalização é o afastamento do saber quanto ao seu lugar de origem e ao seu fundador. A programabilidade refere-se à decomposição e redistribuição do saber de forma progressiva, em consonância com os objetivos de ensino e aprendizagem. Quanto à publicidade, podemos destacar como um processo que valida um documento ou um texto oficial a partir da divulgação e da visibilidade, assim, adquiridas. No que tange ao último procedimento citado pelo autor, está o controle, em que ocorre a verificação da aquisição, pois se testa a boa eficiência do movimento de TD.

Assim, várias nuances atravessam a (re)organização dos saberes quando passam a ser obje-

https://periodicos.unifap.br/index.php/letras

Macapá, v. 9, n. 3, $2^{\circ}$ sem., 2019 
tos de ensino. Com a virada dos estudos linguísticos, a produção textual, sofreu profundas modificações. Os estudos da linguística que têm o texto como objeto teórico numa vertente textual-enunciativa começam a desenvolver-se na Europa, na década de 60 do século XX e, no Brasil, mais tardiamente, a partir da década de 70. Concomitantemente a essa configuração como objeto de estudo, o texto foi caracterizado como objeto de ensino.

Assim, o texto pode ser entendido segundo as mais variadas vertentes teóricas, sob as mais diversificadas perspectivas e métodos de análise. De acordo com Brait (2016, p. 16), Bakhtin refere-se a texto como "uma dimensão linguística atualizada por um sujeito coletivo ou individual, que se caracteriza como enunciado concreto". Desse modo, podemos inferir que o texto pertence a um contexto social, histórico e cultural, portanto, é na interação que se materializa enquanto evento, enquanto acontecimento.

Para Bentes (2004, p. 254), é um ganho para os estudos de Linguística Textual o fato de as condições de recepção e produção do texto passarem a ser consideradas, uma vez que isso significa não mais considerar o texto como uma estrutura pronta, mas como uma manifestação verbal complexa. Desse modo, a autora, com base nos estudos de Koch (1997), elenca três processos a partir dos quais podemos tentar desvelar a complexidade da produção de textos: planejamento, verbalização e construção.

O primeiro processo, que entende a produção textual como uma atividade verbal, diz respeito ao fato de, ao produzir-se um texto, praticarem-se atos de fala. Nesse sentido, a partir da interação por meio da língua, cuja ação ocorre em contextos situacionais, sociocognitivos e culturais, estes enunciados produzirão efeitos no interlocutor. Quanto ao segundo processo, temos a ideia de produção textual como uma atividade verbal consciente, em que devemos considerar as intenções a que o produtor recorre para expor seus propósitos. Já o terceiro processo, que incorpora a noção produção textual como atividade interacional, podemos inferir que o interlocutor está obrigatoriamente envolvido no processo de construção e compreensão de um texto.

Diante do exposto, cabe dizer que um documento como o focalizado nesta pesquisa carrega consigo uma arquitetura conceitual que opta por determinados conceitos de língua, sujeito, texto, gênero, discurso. Assim, torna-se relevante desmontar a configuração teórica de que se reveste tal documento para (de)compor seus objetos de ensino, no caso em pauta, a Produção Textual. Torna-se importante, assim, (re)organizar sua arquitetura conceitual de acordo com as noções/lugares teóricos que estão dessincretizados, apontando que implicações para o ensino decorrem desse movimento de TD. Isto será apresentado na seção a seguir.

\section{A arquitetura conceitual da produção de texto nas OCEM}

A presente análise apropria-se de evidências linguísticas encontradas no nosso corpus, as OCEM, como também dos verbetes que apresentam conceitos explícitos e/ou implícitos no documento e a relação com a teoria da Transposição Didática (dessincretização). Esses dois pontos correlacionam-se da seguinte forma: no documento existem termos que se associam a dados conceitos e estes, por sua vez, encontram-se num estado de dessincretização em relação aos seus lugares teóricos.

Não obstante o documento apresente uma seção de referências bibliográficas, tal dessincretização pode ser observada quando não há citações (diretas ou indiretas) que apontem para filiações teóricas relacionadas à Produção Textual. Assim, o fato de tais referências serem apagadas ao longo do texto é o que suscitou, nesta pesquisa, uma análise aprofundada da engenharia didática a fim de não só desvelar, mas reconstruir as filiações teóricas de que o documento se apropria para a (re)configuração de seus conceitos.

Um primeiro termo que se apresenta de modo significativo no documento é "sistemas semióticos". Isso acontece tanto pela expressiva recorrência no documento, quanto pelo fato de que é uma concepção que parece alinhar os conceitos em torno dela. A seguir, um conceito de 


\section{"Vivemos em um mundo culturamente organizado por mútiplos sistemas semióticos - linguagens verbal e não verbal - pesultado de traballho humano oue foi sedimentado numa relaciõo de convencionalidade.}

Fonte: OCEM (BRASIL,2006, p. 25, grifo nosso)

Nesse sentido, o documento associa a noção de língua(gem) a sistema semiótico, trazendo o aspecto de convenção social como preponderante do processo. Partindo desse pressuposto, "a língua é uma das formas de manifestação da linguagem, é um entre os sistemas semióticos construídos histórica e socialmente pelo homem" (OCEM, 2006, p. 25). Como vemos, a língua é tida como um sistema semiótico a partir do qual a linguagem se manifesta. Portanto, a linguagem também é um sistema semiótico que se organiza a partir de símbolos e signos, conforme podemos observar na definição que o documento traz:

Figura 2 - Definição de linguagem

\section{Um outro ponto essencial, nesse quadro, é o de que, sendo a linguagem uma} capacidade humana de simbolizar e de interagir e, por essa via, condiçấo para que
se construam as realidades, năo se pode dizer que entre os signos que constituem os diferentes sistemas semióticos e o mundo haja de fato uma relaçăo direta.

Fonte: OCEM (BRASIL, 2006, p. 24, grifo nosso).

Partindo desse pressuposto, podemos inferir que, devido ao fato de que a linguagem é simbólica e também é representação social, são as convenções da linguagem enquanto sistema semiótico que estabelecem relação de sentido no mundo. Diante disso, podemos perceber que essa noção advinda da semiótica é a que orienta e atravessa a noção de língua e de linguagem presentes nas OCEM. Nesse viés, como apontam Koch e Elias (2016), a concepção de texto teve que evoluir de uma visão que o colocava apenas como resultado de operações cognitivas, até chegar à sua compreensão como uma entidade multifacetada. É baseado nessa última noção que o documento parece pensar o ensino de produção textual no Ensino Médio.

Segundo o documento, "cabe assinalar que, sendo, porém, uma atividade de construção de sentidos, a interação - seja aquela que se dá pelas práticas da oralidade ou intermediada por textos escritos - envolve ações simbólicas (isto é, mediadas por signos), que não são exclusivamente linguísticas" (OCEM, 2006, p. 25). Portanto, a produção de texto deve ser considerada enquanto atividade sociointerativa e simbólica, uma vez que mobiliza diferentes sistemas semióticos para executar as práticas de linguagem (orais e escritas). Além disso, outros conceitos se apresentam no documento, como por exemplo, os que dizem respeito à noção de texto, trazendo aspectos constitutivos dessa unidade de sentido, conforme os excertos a seguir: 
Figura 3 - Definição de texto

Isso produz uma mudança sensível de paradigma: o texto passa a ser visto como uma totalidade que só alcança esse status por um trabalho conjunto de construçăo de sentidos, no qual se engajam produtor e receptor.

Fonte: OCEM (BRASIL, 2006, p. 21, grifo nosso).

Figura 4 - Texto e textualização

Deve-se ressaltar, aliás, que, quanto mais se aprofunda a compreensão desses aspectos, mais ganha força a idéia de que a existência de um texto depende de que alguém o processe em algum contexto; por isso estudar os fatores que concorrem para a textualização é uma atividade que exorbita o espaço da materialidade textual, mas, inegavelmente, nela se ampara.

Fonte: OCEM (BRASIL, 2006, p. 22, grifo nosso).

De acordo com os excertos acima, extraídos das OCEM, podemos ver alguns direcionamentos acerca do texto, os quais chamam atenção pelo fato de apontarem para três aspectos que engendram a concepção de texto: (1) $\mathrm{O}$ texto é uma totalidade, construtor de sentidos e, neste processo (produção textual), engajam-se produtor e receptor; (2) é uma atividade que exorbita a materialidade textual; e (3) Sua existência depende que alguém o processe num dado contexto.

Diante disso, todas essas definições apontam para o fato de que o texto só existe na interação. Assim, o falante tem papel ativo na mobilização dos conhecimentos, sejam linguísticos, pragmáticos ou interacionais, "em outras palavras, o sujeito sabe o que faz, como faz e com que propósitos faz" (BENTES, 2004, p.254). Portanto, esse jogo interacional - entendido como um processo gerador de sentidos - faz com que o texto seja senão os próprios sentidos que veicula. Assim, vemos as vinculações sociointeracionistas do documento, ao entender a produção textual como um processo que se constrói na relação entre os produtores e receptores de textos.

Quanto a essas definições, podemos observar que são nessas instâncias que os sujeitos constroem suas representações acerca dos diferentes sistemas semióticos, os quais ocorrem diante de um processo de regulação de sujeito para sujeito, isto é, regulado pela interação. Esses sujeitos recorrem ao sistema linguístico de que dispõem para realizar diferentes práticas de linguagem, em diferentes esferas de comunicação, a fim de construir sentidos. Nesse sentido, esse processo parece apontar para uma concepção de texto como atividade verbal consciente (KOCH, 1997), visto que a mobilização de conhecimentos linguísticos, pragmáticos e interacionais vêm a serviço dos propósitos discursivos do processo de interação.

Segundo o texto oficial, "se é pelas atividades de linguagem que o homem se constitui sujeito, só por intermédio delas é que tem condições de refletir sobre si mesmo" (OCEM, 2006, p. 23). Com base nisso, o documento indicia sua filiação aos estudos interacionistas, segundo os quais é importante compreender a teia com que se tecem as relações interpessoais e interativas mediadas pelo uso da língua e, a partir disso, é que o falante se apropria das formas de funcionamento da linguagem. A esse respeito, língua neste documento define-se como apresentado na figura 5 seguinte:

https://periodicos.unifap.br/index.php/letras

Macapá, v. 9, n. 3, $2^{\circ}$ sem., 2019 
Do que foi dito até o momento, pode-se concluir que, desse ponto de vista, a língua é uma das formas de manifestaçăo da linguagem, é um entre os sistemas semióticos ${ }^{4}$ construídos histórica e socialmente pelo homem.

Fonte: OCEM (BRASIL, 2006, p. 25, grifo nosso).

Diante disso, constatamos que é a partir de práticas orais ou de escrita que o usuário recorre ao sistema linguístico para compor seu léxico e apresentar-se ao mundo por meio da linguagem. Considerando ações de natureza linguística, cognitiva e social (KOCH, 1997), as quais convergem na estrutura complexa da Produção de Textos, os interlocutores constroem sentidos que vão além do texto, ao passo que também são co-construídos, num movimento dialético e dialógico, cuja realização se concretiza nas práticas permeadas pelo uso da língua.

Outrossim, no que se refere à produção textual, o documento apresenta a importância de se "conviver, de forma não só crítica mas também lúdica, com situações de produção e leitura de textos, atualizados em diferentes suportes e sistemas de linguagem - escrito, oral, imagético, digital, etc" (OCEM, 2006, p. 31). Portanto, as OCEM dão importância igual à produção oral, escrita, verbal e multissemiótica, levando em consideração os diferentes sistemas semióticos e apontando para uma concepção menos excludente e mais coerente com as faces da produção textual.

\section{Considerações finais}

Nas OCEM, o objeto de ensino Produção Textual, em termos de Transposição Didática (dessincretização), aparece bem configurado, não só do ponto de vista teórico, mas, sobretudo, devido à boa articulação com outros conceitos a ele vinculados. Apresentam-se no documento, concepções que não só atravessam, mas encapsulam nosso objeto de ensino, como a noção de prática, letramento e sistemas semióticos, o que aponta para a pluralidade linguística e a diversidade teórica. Uma implicação decorrente disso é que toda a coerência apresentada entre a disposição de termos e os conceitos aos quais eles se associam, parece conferir uma natureza mais pedagógica e menos técnica ao documento, visto que tal noção liga-se ao processo de produção textual e não ao produto final, pronto e acabado.

A análise dos verbetes indicia que as OCEM se mostram como um documento filiado à concepção textual-enunciativa, posto que o conceito de texto é central, sendo este visto como resultante de um conjunto maior de práticas de linguagem. Logo, a filiação teórica, embora não explicitada com referências, aponta para o fato de que, além dos conceitos estarem fortemente amalgamados, estes aparecem de modo parafrástico no documento, o que parece revelar uma associação aos estudos vinculados à virada sociológica dos estudos linguísticos (Semiótica, Análise Dialógica da Linguagem e Interacionismo Sociodiscursivo).

Vale salientar que o conceito de produção de texto aparece, de fato, muito dessincretizado. Todavia, nesse processo de (re)configuração conceitual, essa noção se apropriou de várias outras concepções para compor seus objetos (oralidade e escrita). Isso indicia um tratamento da Produção Textual como algo mais amplo, que mobiliza produção de sentidos, relação de produçãorecepção, sistemas semióticos, interação, entre outros.

Um aspecto representativo no texto oficial analisado diz respeito ao fato de que a oralidade e escrita são consideradas igualmente relevantes. Não só as práticas orais ganham destaque neste documento, como também ele chama atenção para o letramento multissemiótico que, do ponto de vista dos estudos linguísticos, é um conceito que concede à oralidade o mesmo espaço que é 
dado aos outros sistemas semióticos. Portanto, não se trata de um currículo que visa formar para o mercado de trabalho, mas, sim, orientações teórico-metodológicas para o professor, de modo que possam ajudar na montagem de currículos para formar cidadãos que, a partir do uso da linguagem, possam atuar na sociedade de modo colaborativo, com autonomia e criatividade.

Por fim, cabe dizer que a boa articulação teórica apresentada no documento, ao lado de uma coerência teórico-metodológica, tem outra implicação: faz pressupor um professor (leitor do documento) que tenha conhecimento das teorias com as quais esta proposta curricular fundamenta-se. Isso decorre do fato de que tais concepções estão fortemente dessincretizadas e amalgamadas, a partir de uma interconexão peculiar tanto entre os campos teóricos, quanto entre os próprios objetos de ensino, o que faz das OCEM um marco para (re)construção de currículos de Língua Portuguesa.

\section{Referências}

BENTES, A. C. Linguística textual. In. BENTES, A. C.; MUSSALIM, F. (Orgs). Introdução à linguística: dominios e fronteiras. 4. ed. São Paulo: Cortez, 2004, p. 245-282.

BRAIT, B. O texto nas reflexões de Bakhtin e do Círculo. In: BATISTA, R. O. (Org.) O texto e seus conceitos. São Paulo: Parábola, 2016.

BRASIL. Ministério da Educação e do Desporto. Secretaria de Educação Básica. Orientações curriculares para o ensino médio. Vol. 1. Brasília: MEC/SEB. 2006. (Linguagens: códigos e suas tecnologias).

CHEVALLARD, Y. La transposición didáctica: del saber sabio al saber enseñado. Buenos Aires: Aique, 1991.

FÁVERO, A. A.; TAUCHEN, G.; SCHWANTES, L. Da transposição à compreensão didática: sentidos do conhecimento escolar na educação em ciências. Roteiro, v. 37, p. 325-342, 2012.

KOCH, I. G. V. O texto e a construção de sentidos. São Paulo: Contexto, 1997.

KOCH, I. G. V.; ELIAS, V. M. O. O texto na linguística textual. In: BATISTA, R. O. (Org.) O texto e seus conceitos. São Paulo: Parábola, 2016.

LE GOFF, J. Documento/monumento. In: Enciclopédia Einaudi. V.1. Memória-História. Lisboa: Imprensa Nacional - Casa da Moeda, 1997. p. 95-106.

MACEDO, R. S. Currículo, campo, conceito e pesquisa. Petrópolis: Pontes, 2012.

MARANDINO, M. Transposição didática ou recontextualização? Sobre a produção de saberes na educação em museus de ciências. Revista Brasileira de Educação. 2004, n.26, p. 95-183.

MARCHUSCHI, L. A. Produção textual, análise de gêneros e compreensão. São Paulo: Parábola, 2008.

MOITA LOPES, L. P. Por uma linguística aplicada indisciplinar. São Paulo: Parábola, 2006.

MOREIRA, H.; CALEFFE, L. G. Metodologia da pesquisa para o professor pesquisador. Rio de Janeiro: DP\&A, 2008.

PETITJEAN, A. Importância e limites da noção de transposição didática para o ensino do francês. Fórum Linguístico, 5 (2): 83-116, Florianópolis, jul. dez., 2008.

SILVA, T. T. Documentos de identidade: uma introdução às teorias do currículo. 2. ed. Belo Horizonte: Autêntica, 2005.

SILVA, T. T. O curriculo como fetiche. Belo Horizonte: Autêntica, 2006.

Enviado em: 29/03/2019

Aceito em: 01/07/2019 